\title{
Encyclopedia of Movie Montage The Movie Orphan Twist Directed by David Lean
}

\author{
Jingfeng Fang ${ }^{1, *}$
}

\author{
${ }^{1}$ Shanghai Institute of Visual Arts, Shanghai 201620, China \\ *Corresponding author. Email: 157517424@qq.com
}

\begin{abstract}
Speaking of David Lean, people will think of his representative works such as Lawrence of Arabia, The Bridge on the River Kwai and Doctor Zhivago, which are well-known in the world film history. However, Oliver Twist is seldom mentioned. As the research object, it is rare. As the most representative work of David Lean, it is a pity that it has become an unnoticed talent. In fact, the film is an encyclopedia of montage, a textbook of montage, and even a treasure of montage, waiting for future generations to discover. David Lean did not show off his skills. Every montage was carefully designed to give full play to their magical functions and enhance the dramatic effect of the film. David Lean is a film master of first-class technology and art. He summarizes the achievements of his predecessors on the application of montage for his own use and dares to break through and innovate. This is also the essence of the film's enduring prosperity.
\end{abstract}

Keywords: David Lean, montage, edit, textbook, Oliver Twist

\section{INTRODUCTION}

Montage comes from French architectural terminology, meaning "composition, assembly". English means "cut, edit". It means that the independent shot (video material) taken in the production of the film is selected, chosen, decomposed and assembled to achieve a coherent, fluent, clear meaning, clear theme and artistic appeal of the film.

\section{THE HISTORICAL DEVELOPMENT OF}

\section{MONTAGE}

In the early days of the film's birth, the film was shot with a fixed point of view and a single shot. Without space-time cutting and combination, there would be no montage. Even though the scenes shot in different scenes were connected to narrate, the whole scene was shot from the same location. The connection of the scenes was primitive, and no montage was used. It wasn't until D.W. Griffith filmed The Desolate Villa that parallel montage was first used in film history. In the film, one story line shows a woman and her son falling into the hands of a burglar, and the other shows a woman's husband rushing home to rescue them. Griffith crossed the two story clue, and the two line appeared back and forth alternately, creating a strong suspense effect. He succeeded in capturing the attention of the audience, creating the same dramatic effect as literature, drama and other arts, and taking a successful step for the film to become an independent art. The earliest and most successful parallel montage application in film history was Griffith's "last minute rescue". In 1916, the film Intolerance Griffith parallel editing of actions that will take place in different locations, breaking away from the constraints of real time, breaking the traditional dramatic narrative principles, creating a unique narrative way that truly conforms to the laws of film art, and making the film narrative more dramatic and visual tension. Under this psychological effect, the audience is forced to produce rich associations, time and space to achieve the artistic effect of enlargement and extension.

Although Griffith was the first director to use parallel montage, he used it only with his own intuition, and only used montage as his narrative tool. He did not systematize, theorize and professionalize Montage, nor did he realize its great potential and great effect on film development. It is the former Soviet filmmakers who really put forward the concept of montage and perfected it, such as Golding, Kurishov, Eisenstein and Pudovkin, They have explored and summarized the laws and theories of montage one after another, and formed the montage school around the 1930s. Their theory of montage has had a profound impact on film creation. The emergence of the Montage School has played a decisive role in promoting the development of world films, making films a solid step towards becoming an independent art form, and the film has formed its own language. Since then, the montage technique has been applied and practiced by film directors all over the world, and a new montage technique has been 
developed, which has created a greater space for film development.

David Lean, a British film mogul, entered the studio in 1927 and has served as an acting director, assistant director and editor, earning the reputation of "Britain's First Editor". Lean directs 18 films and writes 27 plays, which have been nominated 56 times and won 27 Oscar awards. In Cannes, Berlin, Venice three major art film festivals 4 nominations, 2 awards. In 1990, the American Film Association awarded him the Lifelong Achievement Award.

David Lean was deeply influenced by the Montage School. He used a lot of montage techniques to make films, which had both summary and creative development. Speaking of David Lean, people will think of his representative works such as Lawrence of Arabia, The Bridge on the River Kwai and Doctor Zhivago, which are well-known in the world film history. However, Oliver Twist is seldom mentioned. As the research object, it is rare. As the most representative work of David Lean, it is a pity that it has become an unnoticed talent. In fact, the film is an encyclopedia of montage, a textbook of montage, and even a treasure of montage, waiting for future generations to discover. David Lean did not show off his skills. Every montage was carefully designed to give full play to their magical functions and enhance the dramatic effect of the film. David Lean is a film master of first-class technology and art. He summarizes the achievements of his predecessors on the application of montage for his own use and dares to break through and innovate. This is also the essence of the film's enduring prosperity.

\section{MONTAGE TECHNIQUES IN OLIVER TWIST}

Oliver Twist tells the story of Oliver, a child who grew up in a church slum, who was sent to a coffin shop as an apprentice at the age of 9 and fled to London alone because of long-term abuse. Later, Oliver was tricked by Fagan the leader of the thieves to learn to steal with a group of children. One day Oliver was caught as a thief. Oliver fainted in court and was taken in by a kind gentleman. Oliver volunteered to return the book for the old gentleman, and was caught back in the den of thieves. Nancy, who grew up in the den of thieves, felt pity for her children and decided to save Oliver. Nancy found the old gentleman and told him what had happened. She promised to bring Oliver to see him at noon the next day. But all this was seen and reported to Fagan by one of his children. Fagan's partner Bill killed Nancy in the room in a fit of rage. Soon, the whole city was informed of Nancy's murder. Fagan was subdued by the police, and Bill was punished for falling off the roof when he fled. Oliver led his grandfather's hand to his home.
David Lean's montage philosophy is that any hint of hardship and depression is murder of the film. There's a special thing in the film, and we have to protect it from damage. The opening shot of the movie should be one of the best opening scenes in the history of the film, and it is also a model of the application of montage techniques. There were only 27 shots in the opening, but the director used four montage techniques: metaphorical montage, repetitive montage, continuous montage and Lyric montage. The scene in which Bill killed Nancy was another wonderful one, but also more focused on the application of montage, there are three kinds: reflection montage, psychological montage, sound and painting montage. In addition, there are two other montages: contrast montage and cross montage. The film uses nine montage techniques, the real montage "encyclopedia".

\section{A. The metaphorical montage}

Metaphorical montage reveals the internal relationship between two things through two different shots and the two shots are basically similar. This similarity refers not to the similarity of the content of the picture, but to the essential similarity of the picture. The purpose is to deepen the content, let the audience understand the meaning of the picture, in order to arouse the audience's association, understand the director's moral and appreciate the emotional color of the event. This technique was first used in the film Mother directed by Pudovkin. The scenes of the workers' parade are connected with those of the spring thawing of the glacier, which is a metaphor for the unstoppable revolutionary movement.

Metaphorical montage combines great generalization with extremely concise expressive techniques, often with strong emotional appeal. However, the use of this technique should be cautious. Metaphor and narration should be combined organically to avoid being too rigid and far-fetched. At the beginning of Orphan Twist has no narration, no dialogue, only background music and sound effects. It connects the pictures by montage, and implies the inner connection of things by pictorial metaphor.

The film's first shot, the vision, the tilted horizon, Oliver's mother stumbled into the camera. Before the storm came, the mother was about to give birth, but she was in the wilderness, no place to live, no one to help. Using oblique lines to metaphor mother's fate is full of variables and uncertainties.

The second shot, empty shot, close shot, dead branches, a dead leaf falling down. Making use of the falling leaves again emphasizes the uncertain fate of mother.

Fourteenth shot, empty shot, close shot, thorny thorns sticking out of the darkness. "Thorns" make 
people feel uncomfortable, which can remind people of the pain after being stabbed. The director used this picture to metaphor the pain of pregnant women, and transmitted the pain to the audience, so that the audience can also feel the "pain" of the mother before parturition. There are three metaphorical montage techniques used in the section, each of which is a model of metaphorical montage.

\section{B. The repeat montage}

Repetitive montage is the choice of typical things as narrative carrier, and repeated in the shot, that is, emphasis is also the continuation of the development of events. It is equivalent to the way of repetition in literature or in artistic works, that is to say, the pictures shot or important scenes, characters, actions and objects with certain implications are repeatedly presented at critical moments through careful conception, so as to highlight the changes of fate, personality and psychology of the characters, so as to achieve the purpose of characterizing the characters and deepening the theme.

At the beginning of the film, director choose the typical things that can best show the storm intensity, such as white clouds, withered branches, thorns, grasses, water depressions, and so on. Repeated use of these typical things in the lens, the performance of Storm Characteristics and development process, through the performance of storm highlights the tragic experience of film characters.

The first shot and the fifth shot and the eleventh, both scenery and content, are repetitive. The first shot is white clouds, and the fifth shot the white clouds become dark clouds, and move quickly, covering the sky, the eleventh shot dark clouds cover the sun, the sky is dark.

The second shot, the fourth shot and the 20th shot are repetitive. In the second shot, the dead branches are still and the leaves fall vertically; in the fourth shot, the dead branches are blown by the wind and begin to shake, while the leaves are flying across; in the 20th shot, heavy rain strikes the branches and the branches shake violently.

The third shot and the 22nd shot are repetitive. In third shot, the contents are grass and water pools, the grass stands still and the water surface is like a mirror; In 22nd shot, the grass sways violently as the wind sweeps, the rain pours violently on the water.

Movies are the product of space-time imagination with audience participation and recognition. In this reproductive picture, the audience reconstructs the development process of the storm through imagination, and the storm constructed by the audience surpasses the storm in reality, is more violent and tense than in reality. This is the magic of montage, which produces the effect of $1+1>2$.

\section{The continuous montage}

Continuous montage is a rhythmically continuous narrative method along a single plot clue, in accordance with the logical sequence of events, it was one of the first montage forms to be used. This narrative is naturally smooth, simple and smooth, but because it cannot directly show the simultaneous plot, it is seldom used alone in a film, mostly mixed with parallel, crossmontage.

In the beginning of Oliver Twist has only one story clue, from the emergence of young mothers to the pain before delivery, painful struggle, found the orphanage, and finally gave birth to little Oliver smoothly, it is suitable for the use of continuous montage narrative. The storms intersperse in the middle, which strengthens the dramatic nature of the story and the tragic nature of the characters.

This technique is also used in another section, in the scene of "orphanage children begging for more food": one hand reaches for the straw stick and starts drawing lots, when Oliver draws the short lots, the other children dispersed in tension and panic. Oliver walked through the aisle beside the table, and rows of nervous little faces were watching him. In the silence, Oliver begged church administrators for more food, followed by a series of officials' surprised faces, then cut it into a label that said, "This child sells five pounds." and Mr. Solbelly's voice: "I bought it." No wonder some people say that David Lean's blood is not blood, but celluloid, and he himself does not deny this: "Yes, I really have no choice, that's how I feel about movies." Story telling with shot, rigorous structure, careful logic, concise lens, but not monotonous continuous Montage textbook-style cases.

\section{Lyric montage}

Lyric montage is a kind of thought and emotion that transcends the plot while guaranteeing the coherence of narration and description. Jean Mitry French film theorist, pointed out that its original intention was not only to narrate stories, but also to render vividly, and more emphasis was placed on the latter. The most common, most easily felt Lyric montage by the audience, often after a narrative scene, appropriately cut into the empty shot symbolizing emotional feelings.

When the young mother was about to give birth and was caught in a storm, at the last moment, she finally found the slum and gave birth to little Oliver. Next came an empty shot, the clouds dispersed, revealing the sun. There is no direct relationship between the picture and the plot, but the appropriate expression of the character's feelings at that time, Lyric montage is 
actually the sublimation of emotional thoughts beyond the plot.

\section{E. Reflection montage}

The things described and the things used as metaphors are in the same space, they are interdependent: either in order to contrast the event, or to determine the reaction between things connected together, or in order to reveal similar events contained in the plot through reflective association, so as to act on the audience's senses and consciousness.

In this film, the scene of Bill killing Nancy, When Bill picks up the weapon and tries to hit Nancy on the head, the camera cuts to the dog running to the door because of fear. The dog scratch, bite the door and try to get out of the room, while the voice over the picture came from time to time with the sound of a murderous weapon hitting Nancy 's head. By expressing the fear of dogs and the behavior of dogs, the audience can associate with Lancy's murderous behavior. This imagination can stimulate the audience's sensory response to this photographable event more than the direct use of pictures. This technique was the creative application of David Lean, and it was not until decades later that Hitchcock, the master of suspense, took on a new height.

\section{F. Psychological montage}

Psychological montage is an important method of psychological description of characters. It vividly shows the inner world of the characters through the combination of pictures and sound. It is often used to express the spiritual activities of the characters, such as dreams, memories, flashes, illusions, reverie and thinking. This montage mostly uses cross-cutting and interpolation techniques in splicing techniques. It is characterized by the fragmentation of pictures and sounds, the incoherence of narration and the leap of rhythm. Sound and picture have strong subjectivity of the characters in the play.

When Bill killed Nancy, Bill pulled the curtain up in a panic, and the dog was still shaking with fear. Bill sat down in a panic, rose again, and covered Nancy's body with a quilt. Then he sat down again, stared at the shivering dog, and at Nancy's hand, which was exposed. The picture cuts to Nancy's dressing table, an empty bed. The camera pushed to Bill's face close-up and Nancy's voice rang. Bill imagined Nancy saying to the camera: Fagan lied, I didn't tell you, He cheated you. Bill's close-ups and Fagan's close-ups switch back and forth. Bill picked up the hammer and hit Fagan. In the picture, Fagan's body smoothly superimposed into Nancy's body, Next picture jumps to Bill's flustered expression. Through illusion and reverie, the audience can understand Bill's psychological changes at that time, which makes the characters fuller and the story more dramatic.

\section{G. Sound and painting montage}

Sound and painting montage is generally divided into two forms: the unity of sound and painting and the contraposition of sound and painting. The unity of sound and painting is also called synchronization of sound and painting. Sound and sound body in the picture appear and disappear at the same time. That is to say, the image in the picture coincides with the sound it emits.

In 1928, Soviet film master Eisenstein and others published the statement "The Future of Sound Film", advocating the use of "sound as an independent factor from visual image", emphasizing that sound and visual cannot be synchronized. So there is a sound-picture counterpoint. Sound-picture counterpoint is also called separation of voice and painting, which means that sound and picture are not synchronized and unified. It refers to the expression of different aspects of sound and picture at the same time from a specific creative purpose. The relationship between the two forms a "counterpoint" so as to express the content and theme of film and television more profoundly.

In the scene Bill killed Nancy, the separation of sound and painting in the sound-picture montage was used. Bill picked up the hammer and hit Nancy. The dog was scared and ran to the door. He scratched the door with his claws and tried to escape from the room. The voice is not consistent with the picture. The emphasis of voice expression is on the sound of a murderous weapon hitting Nancy's head, rather than the sound of a dog scratching the door and biting the door. Using the separation of sound and picture to expand the visual space skillfully, the audience can believe the "real" space atmosphere created by the film, which enhances the credibility and tension.

\section{H. Contrast montage}

Contrast montage is similar to the contrastive description in literature, that is, through the strong contrast of picture content (such as poverty and wealth, bitterness and happiness, life and death, nobility and inferiority, victory and failure) or form (such as shot size, color warmth, voice strength, movement and silence), it produces conflicting effects, in order to express the creator's meaning or strengthen the content and thought expressed.

At the beginning of the film, in the orphanage dining room, the table only has a bowl of sparse soup and a piece of bread. The orphans eat carefully and dare not waste a grain of rice. The next scene is the church administrators eating, the table is full of delicious dishes, big fish and meat piled up like mountains, deans 
and officials open their mouths, eating full of oil. By contrast montage has achieved a strong dramatic effect, forming a clear contrast, the life of orphans is like in hell and the life of church administrators is like in heaven. The exploitation of orphans by the Church is clear at a glance and reinforces the theme.

\section{Cross montage}

Cross montage, also known as alternating montage, splices two or more plot clues occurring in different regions at the same time rapidly and frequently. The development of one clue often affects the other. Each clue is interdependent and finally converges. This editing technique can easily cause suspense, create a tense and intense atmosphere, and enhance the sharpness of contradictions and conflicts. It is a powerful way to grasp the audience's emotions. Thrillers, horror movies and war movies often use this method to create chase and suspense.

Most of the films are continuous editions, which are based on the sequence of time, and only a few use cross-cutting. There are three clues in the film: one clue is that Oliver was stolen by the thieves and abetted Oliver to steal; the other clue is that old gentleman Robert Browne tried to find Oliver; another clue is that a mysterious man named Menckens found Fagan and paid him to watch Oliver and kill him if necessary to prevent Oliver from meeting his grandfather. Three clues are interleaved and edited and they develop independently and interact with each other. The plot is full of suspense and ups and downs. The audience was riding a roller coaster under the control of three clues, and was worried about Oliver's fate. Eventually Oliver was reunited with his grandfather, and the bad guys were punished. The audience's hanging heart was lowered. The use of this technique creates a strong sense of suspense and strengthens the dramatic nature of contradictions and conflicts.

\section{CONCLUSION}

David Lean is a world-class film master of technology and art. He is a heritage and an innovator. In the application of montage, summed up the achievements of the predecessors for their own use, but also dare to break through innovation and enrich the artistic and technical methods of film. This is why the film can last forever. We study masters, learn from the experience of predecessors, study and understand, and then innovate, only stand on the shoulders of giants to see higher and go further.

\section{References}

[1] (US) Harren Kennedy. Interview with David Lean. Translated by Wu Tiandi. Journal of Beijing Film Academy Published in $1988 \cdot 02$.
[2] Wang Cunlei. David Lean and His Screen World Journal of Beijing Film Academy Published in 1988.2.

[3] Eisenstein. The Future of Audio Movies (Statement). Translated by Yu Hong. Journal of Beijing Film Academy Published in 1987. 02.

[4] Xie Xiaoting. An analysis of montage theory in "one night romance" Theatre house, Published in 02 (I), 2017.

[5] Jean Mitri. Film aesthetics and psychology. Translated by Cui Junyan. Jiangsu literature and Art Press, Published in 2012.09.

[6] Christopher Kenworthy. Translated by Wei Junyan. Master shot. Electronic Industry Press, Published in 2013. 01. 